\title{
Uma renovação curricular muito além do currículo
}

Maria Helena Guimarães de Castro MARIA INÊS FINI

A Diversificação do Currículo do Ensino Médio na rede pública de São Paulo é uma proposta para apoiar a realização dos projetos dos jovens paulistas.

\section{Olhar da Juventude para o ensino médio}

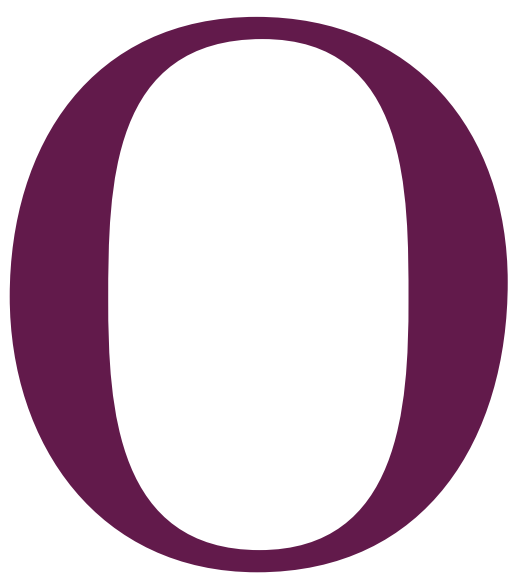

que os jovens esperam das escolas de nível médio?

Por que o debate sobre o ensino médio está na agenda das políticas educacionais de diferentes países, desde meados dos anos 90, sem conseguir desenvolver programas que atendam as expectativas dos jovens?

Quais os caminhos possíveis para flexibilizar percursos de aprendizagem que ofereçam alternativas de formação mais próximas aos anseios da juventude?

Essas são as principais perguntas que norteiam a proposta de diversificação curricular do ensino médio na rede pública estadual de São Paulo.

* Maria Helena Guimarães de Castro é mestra em Ciência Política, docente daUNICAMPeatualSecretária deEstado daEducaçãodeSãoPaulo. MARIA INÊS FINI é doutora em Educação, professora aposentada da UNICAMP, atual Assessora de Currículo e Avaliação da Secretaria de Estado da Educação. 
Respaldada nos instrumentos legais vigentes, como a Lei de Diretrizes e Bases da Educação Nacional - LDB, de 1996; as Diretrizes Nacionais do Ensino Médio, promulgadas em 1998; o Plano Nacional de Educação PNE, aprovado em 2000; e o Plano de Desenvolvimento da Educação - PDE, lançado pelo MEC em abril de 2007, a proposta busca flexibilizar o currículo do ensino médio sem prejudicar a formação geral a que todos os alunos têm direito.

A proposta tem como eixo central a melhoria da qualidade, com ênfase nas competências e habilidades básicas necessárias à preparação dos jovens para o mundo da vida e continuidade dos estudos. Respeitando as diferentes opções e desejos da juventude, busca-se também abrir alternativas de formação que possam oferecer aos jovens melhores condições de integração ao mundo do trabalho.

Muitas vezes atribuímos aos jovens expectativas de mudanças que não condizem com a trajetória histórico-social das oportunidades vislumbradas para a maioria deles.

É verdade que a sociedade atual busca ampliar as possibilidades de integração social da juventude por meio de sua participação intensiva em processos educacionais formais ou não e seu gradual e contínuo acesso a múltiplos bens culturais. Também é verdade que inúmeras pesquisas nacionais e internacionais indicam que educação e trabalho são de longe os temas que mais interessam aos jovens.

No entanto, dados oficiais e de pesquisa indicam que a carência de oportunidades e de integração socioeconômica e cultural para a juventude colocam o Brasil como um dos países com os maiores índices de assassinatos de jovens em relação ao número de habitantes, sendo as vítimas principalmente homens de baixa renda, com cerca de 20 anos.

De acordo com o excelente Relatório Final do estudo Juventude Brasileira e Democracia - participação, esferas e políticas públicas, até mesmo as questões relacionadas à violência, segurança e criminalidade, que fazem parte das principais apreensões dos jovens em todas as regiões brasileiras, estão associadas às questões relativas ao desemprego, má distribuição de renda, desigualdade social, drogas e falta de oportunidades e qualidade da educação.

\section{O mesmo Relatório afirma que}

O lugar do trabalho entre as preocupações dos(as) participantes confirma o que vem sendo apontado em diversos estudos, ou seja, que a incerteza e a apreensão com a busca ou perda de postos de trabalho - processos diretamente relacionados com a obtenção do primeiro emprego e a falta de oportunidades no mercado - são uma constante na vida dos(as) jovens, especialmente, daqueles(as) dos setores populares que desde muito cedo sofrem as pressões para a inserção no mundo do trabalho.

A educação, sobretudo a escolar, é vista como passaporte para um "futuro mais estável" ${ }^{1}$.

Recente pesquisa do IBGE, a PNAD 2006, mostrou que mais de mais de $37 \%$ dos jovens de 15 a 24 anos estão fora da escola, muitos deles sem completar o ensino fundamental.

De acordo com a mesma pesquisa, São Paulo apresenta as melhores taxas de cobertura líquida dos jovens de 15 a 17 anos no País. Mas ainda assim observase que apenas $65 \%$ dos jovens ingressantes concluem o ensino médio.

Considerando que $85 \%$ dos jovens que freqüentam o ensino médio estão na escola pública, tornam-se imprescindiveis ações e medidas voltadas para a reestruturação da educação, especialmente no nível médio.

\section{Olhar da Secretaria da Educação para o Ensino Médio}

Em agosto de 2007, a Secretaria de Estado da Educação de São Paulo definiu um programa de 10 metas a serem alcançadas até 2.010, diretamente ligadas à melhoria da qualidade da educação básica da rede pública de educação, que envolvem e apóiam a reformulação do ensino médio no estado.

São elas:

1. Todos os alunos de oito anos plenamente alfabetizados.

2. Redução de $50 \%$ nas taxas de reprovação da $8^{\text {a }}$ série.

3. Redução de $50 \%$ nas taxas de reprovação do Ensino Médio.

4. Implantação de programas de recuperação de aprendizagem no Ensino Fundamental e Médio.

5. Aumento de $10 \%$ nos índices de desempenho do Ensino Fundamental e Médio nas avaliações nacionais e estaduais. 
Muitas vezes atribuímos

aos jovens expectativas

de mudancas que

não condizem com a

trajetória histórico-

social das oportunidades

vislumbradas para a

maioria deles.
6. Atendimento de $100 \%$ da demanda de jovens e adultos de Ensino Médio com currículo diversificado.

7. Implantação do Ensino Fundamental de nove anos, com prioridade à municipalização das séries iniciais ( $1^{\underline{a}}$ a $4^{\underline{a}}$ séries).

8. Programas de valorização dos professores, formação continuada e capacitação das equipes.

9. Descentralização e/ou municipalização do programa de alimentação escolar nos municípios ainda centralizados.

10. Programa de obras e melhorias de infra-estrutura das escolas.

Em decorrência, foram desencadeados ações e projetos que visam apoiar todos os atores do sistema público de educação para o alcance das metas.

Em relação às metas 1 e 2, o Programa Ler e Escrever impulsiona a melhoria da aprendizagem nas séries iniciais e busca promover a alfabetização plena aos oito anos. Trata-se de apoiar os professores com o trabalho cotidiano de estagiários em sala de aula além de capacitação e acompanhamento direto de professores e gestores com o auxílio de amplo material didático para professores e alunos.

As metas 3, 4, 5 e 6 exigiram uma completa reformulação curricular para o ensino regular e EJA e a implantação de programas emergenciais de recuperação intensiva e paralela.

Os resultados do SARESP 2005 apontavam para a necessidade de imediata intervenção junto à rede estadual com programas especiais de apoio a professores $\mathrm{e}$ alunos para prover a reposição de estruturas fundamentais da Língua Portuguesa e da Matemática, que são re- quisitos para o sucesso dos alunos em qualquer projeto de ensino.

Para este fim, estruturou-se um período inicial de recuperação intensiva de 42 dias, já articulado aos princípios da nova proposta curricular, com ênfase na recuperação (reposição) de estruturas lingüísticas e lógicomatemáticas.

Foi elaborado para 2008, amplo material de apoio, na forma de jornal para os alunos e de revistas para os professores, bem articulados entre si e com indicações claras das competências e habilidades a serem desenvolvidas pelos alunos em cada série escolar, nas áreas de recuperação de Matemática e da Língua Portuguesa, mas no contexto das demais disciplinas do currículo.

Foi dada ênfase à Língua Portuguesa nas atividades que envolvem conteúdos de História, Inglês, Educação Física, Arte e Filosofia.

As estruturas matemáticas foram trabalhadas também em atividades envolvendo Ciências, Química, Física, Biologia e Geografia. Espera-se que essa abordagem interdisciplinar possa sensibilizar os professores para 0 trabalho no resto do ano letivo.

Ao final desse período, os estudantes realizarão provas de Língua Portuguesa e Matemática e os resultados servirão de apoio aos professores para a indicação de alunos que ainda necessitarão de apoio para a recuperação dessas estruturas.

Para eles, será realizada uma outra recuperação paralela, no contra-turno e aos sábados, começando no mês de maio, também com apoio de material para alunos e professores.

Esses esforços se deram em função do reconhecimento das necessidades reais dos alunos para que pudessem interagir com chances de mais e melhor aprendizagem na nova proposta curricular.

\section{Grande levantamento documental e de boas práticas}

\section{Para atender a uma educação à altura dos desafios} contemporâneos, a Secretaria da Educação do Estado São Paulo desenvolveu uma nova proposta curricular para os níveis de ensino Fundamental II e Médio.

Esse processo partiu dos conhecimentos e das experiências práticas já acumulados, ou seja, da sistematização, revisão e recuperação de documentos, publicações e diagnósticos existentes e do levantamento e análise dos resultados de iniciativas e projetos realizados. 
Com o intuito de fomentar o desenvolvimento da proposta curricular, a Secretaria desenvolveu duas ações complementares.

Na primeira, realizou um amplo levantamento do acervo documental e técnico pedagógico existente. $\mathrm{Na}$ segunda, desencadeou um processo de consulta a escolas e professores, para identificar, sistematizar e posteriormente divulgar as boas práticas existentes nas escolas de São Paulo.

Na primeira consulta, realizada no período de 15 de outubro a 30 de novembro de 2.007 , foram registrados 3.071 relatos completos de experiências de sucesso de gestão da sala de aula e da escola.

Essas experiências, devidamente analisadas e comentadas, comporão um acervo permanente à disposição dos profissionais da rede estadual. Esse procedimento será novamente adotado ao final de cada período letivo pois, articulando heranças e conhecimentos pedagógicos com experiências escolares de sucesso, a Secretaria pretende que essa ação seja o início de uma contínua produção e divulgação de subsídios que incidam diretamente na organização da escola como um todo e na dinâmica da sala de aula.

As características principais da proposta curricular são: respeito ao saber já construído e foco em orientações para gestão do currículo na escola e orientações para gestão da aprendizagem na sala.

Para apoiar o trabalho de gestores e professores, foram produzidos vários documentos que explicitam a proposta e servem de subsídios para o trabalho da equipe escolar: Documento Básico, Cadernos do Gestor e Cadernos do Professor.

O Documento Básico apresenta os princípios e conceitos da Proposta Curricular e as concepções das diferentes áreas de conhecimento, que compõem a educação básica, e a apresentação de objetivos e conceitos estruturantes de cada disciplina destas áreas.

Os Cadernos do Gestor apresentam sugestões de organização do trabalho dos especialistas responsáveis pela gestão do currículo na escola. Contêm propostas de agenda, cronograma, atividades e organização de recursos para apoiar o trabalho do diretor, do professor coordenador, dos assistentes técnico-pedagógicos - ATPs e do supervisor. São quatro cadernos, sendo um por bimestre.

Os Cadernos do Professor propõem atividades docentes para todas as aulas, em todas as séries e disciplinas.
São organizados por bimestre com indicação clara das competências e habilidades a serem desenvolvidas pelos alunos, em cada tema ou tópico dos conteúdos. Contém sugestão de aulas, sugestões de material complementar, propostas de avaliação articuladas ao SARESP e projetos de recuperação paralela.

Para apoiar a implantação da proposta foram produzidos:

- 268 originais para impressão para professores e gestores, totalizando mais de 11.240 páginas.

- $20 \mathrm{CDs}$ com textos, imagens e áudio para apoio ao trabalho docente.

- Videoproducers para orientação do trabalho docente, por bimestre/disciplina.

- 1 site interativo e informativo.

- Aplicativo para registro de experiências de gestão do currículo (escola e sala de aula).

- Ferramentas de trabalho colaborativo entre as equipes.

- Ferramentas de pesquisa junto à rede.

Para a implantação da proposta curricular, a Secretaria oferecerá forte apoio aos profissionais da rede. Para isto foram desenvolvidas inúmeras ações de capacitação por meio da Rede do Saber, que é a rede de formação continuada de professores e especialistas em serviço e canal de comunicação da Secretaria Estadual que opera por meio de vídeo-conferência e ferramentas web.

A Secretaria está finalizando também a reestruturação da Teia do Saber que é um programa de formação continuada para professores e especialistas e vai definir os novos programas de formação para supervisores, diretores, professores coordenadores e professores de todas as disciplinas, inclusive professores de EJA.

Todos em nível de pós-graduação lato sensu. Para isso, espera estabelecer parcerias com instituições de ensino superior com notória especialização, nas áreas de formação definidas pela Secretaria.

\section{Base comum de conteúdos, competências e habilidades.}

\section{Ao elaborar e apresentar uma proposta curricular}

básica e comum a todos os alunos, a Secretaria procurou também cumprir seu dever de promover ações para garantir a todos, uma base comum de conteúdos, competências e habilidades para que, de fato, nossas escolas funcionem em rede. 
